\title{
A Promising, Novel Radiosensitizer Nanodrug Complex for Oral Cavity Cancer: Cetuximab and Cisplatin-Conjugated Gold Nanoparticles
}

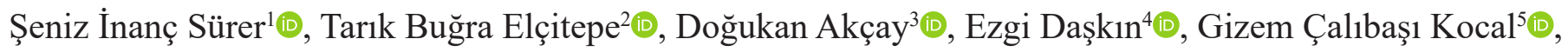 \\ Zümre Arıcan Alıcıkuş ${ }^{3}$, Görkem Eskiizmir ${ }^{6}$ (D, Kerim Yapıc1 ${ }^{7}$, Yasemin Başbınar ${ }^{5}$ (D) \\ ${ }^{1}$ Department of Medical Biochemistry, Dokuz Eylül University School of Medicine, İzmir, Turkey \\ ${ }^{2}$ Department of Energy Science and Technology, Cumhuriyet University, Sivas, Turkey \\ ${ }^{3}$ Department of Radiation Oncology, Dokuz Eylül University School of Medicine, İzmir, Turkey \\ ${ }^{4}$ Department of Translational Oncology, Institute of Health Sciences, Dokuz Eylül University, İzmir, Turkey \\ ${ }^{5}$ Department of Translational Oncology, Institute of Oncology, Dokuz Eylül University, İzmir, Turkey \\ ${ }^{6}$ Department of Otolaryngology-Head and Neck Surgery, Manisa Celal Bayar University School of Medicine, Manisa, Turkey \\ ${ }^{7}$ Department of Chemical Engineering, Süleyman Demirel University, Isparta, Turkey
}

Background: Nanomedicine has provided promising tools for the imaging, diagnosis, and treatment of cancer. Gold nanoparticles (GNPs) may be useful in enhancing the efficacy of radiotherapy, such as radiosensitization, in cancer therapy.

Aims: To develop a nanodrug complex containing cetuximab (C225, CTX) and cisplatin (CDDP) conjugated with GNPs and to investigate its cytotoxic effects on oral cavity cancer cells when combined with radiotherapy.

Study Design: In vitro cell culture study.

Methods: The GNPs were synthesized and successfully conjugated with cetuximab and cisplatin. Cell viability was monitored by the xCELLigence real-time cell analysis (RTCA) single-plate (SP) system in GNP-treated UPCI-SCC-131 cells for 48 hours. Cells with/without
GNPs were irradiated with 6 MV X-rays, and colony formation was assayed to investigate the long-term effects of GNPs and the nanodrug complex after irradiation on radiotherapy-resistant oral cavity cancer cells.

Results: The GNPs entered the tumor cells, and GNP-CDDP $(P<$ $.0001)$ and GNP-CDDP-CTX $(P<.0001)$ were shown to cause a decrease in cell viability. GNP and GNP-CTX combined with radiotherapy led to greater reduction on UPCI-SCC-131 colony numbers, than radiation alone $(P=.0369)$ and radiation with free CTX, with sensitizing enhancement ratios of $1: 2$ and $1: 9$, respectively.

Conclusion: The cetuximab and cisplatin-conjugated gold nanodrug complex has a great potential to increase cytotoxicity and overcome resistance to radiotherapy, in the treatment of oral cavity cancer.

\section{INTRODUCTION}

Oral squamous cell carcinoma (OSCC), a highly aggressive cancer type, is the most common type of head and neck cancer, with morbidity and mortality worldwide. ${ }^{1,2}$ Unfortunately, despite advances in the field of cancer treatment, there has been no improvement in the oncological outcomes (locoregional control, overall- and disease-free survival). Currently, the treatment modalities for OSCC are surgery, radio-chemotherapy, and combined treatments. Surgery is frequently performed though significant challenges persist, particularly oral cavity reconstruction and locoregional failure. Moreover, the radio-resistant biology of OSCC is the major limitation for combined radiotherapy \pm chemotherapy. Therefore, new and innovative treatment strategies are urgently required to overcome these clinical problems and enhance the efficiency of cancer treatment.

Recent advances in nanotechnology have enabled the development of several nanoparticles $(1-100 \mathrm{~nm})$ for use in diagnosis, gene/drug delivery, bioimaging, and cancer therapy. ${ }^{3-5}$ Metal-based nanoparticles with high atomic numbers, which may improve the therapeutic index of radiation therapy, are promising agents for cancer treatment because of their small size, drug-carrying capacity, photothermal effects, and ability to increase sensitivity

Corresponding author: Yasemin Başbınar, Department of Translational Oncology, Institute of Oncology, Dokuz Eylül University, İzmir, Turkey e-mail: ybaskin65@gmail.com

Received: February 2, 2021 Accepted: June 3, 2021 • DOI: 10.5152/balkanmedj.2021.21013

Available at www.balkanmedicaljournal.org

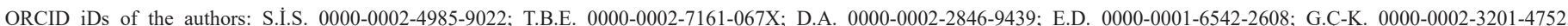
Z.A.A. 0000-0002-5445-6797; G.E. 0000-0002-3125-8288; K.Y. 0000-0002-3902-9375; Y.B. 0000-0001-9439-2217.

Cite this article as:

İnanç Sürer S, Buğra Elçitepe T, Akçay D, et al. A promising, novel radiosensitizer nanodrug complex for oral cavity cancer: Cetuximab and cisplatin-conjugated gold nanoparticles. Balkan Med J. 2021;38(5):278-286.

Copyright@Author(s) - Available online at http://balkanmedicaljournal.org/ 
to radiotherapy. ${ }^{6}$ Among them, gold nanoparticles (GNPs), wellknown metal-based nanoparticles, are suitable candidates as nanocarriers due to their surface area, drug-carrying capacities, and biocompatibility. ${ }^{7}$ The literature indicates that GNPs may reduce cancer viability in a dose-dependent manner, and increase the radiosensitivity of cells due to their photoelectric absorption of photons. $^{8-10}$ Therefore, the conjugation of GNPs with other molecules such as antibodies, anti-cancer agents, or vitamins might enhance the effects of radiotherapy and increase tumor cytotoxicity.

Currently, it is well known that the epidermal growth factor receptor (EGFR) is highly expressed in cancer cells in various cancers including breast, colorectal, head, and neck cancers. ${ }^{11-13}$ In head and neck cancers, overexpression of EGFRs is associated with an aggressive phenotype, poor prognosis, and resistance to cancer treatment. ${ }^{14}$ Cetuximab (CTX) (Erbitux ${ }^{\circledR}$, Merck) is a chimeric monoclonal antibody against EGFR and has been widely used in the treatment of head and neck cancers in recent years. It enables binding of the extracellular region of EGFR with high affinity, thereby inhibiting EGFR activation, stimulating apoptosis, and inhibiting cell cycle progression, tumor cell invasion, and angiogenesis. ${ }^{15,16}$ The combined treatment with CTX shows synergistic activity with conventional methods such as radiotherapy ${ }^{17}$ and chemotherapy. ${ }^{18}$ Due to the clinical importance of CTX, researchers have shown great interest in drug-loaded nanoparticles that are actively targeted to specific overexpressed surface proteins, such as EGFR, to enhance their anti-cancer potential. The purpose of this experimental study is to develop a new, innovative nanodrug complex using GNPs as a nanocarrier, cisplatin (CDDP) as a cytotoxic agent, and CTX for active targeting; and to evaluate the cytotoxic and radiosensitization effects of this nanodrug complex in a radiotherapy-resistant oral cavity cancer cell line in vitro.

\section{MATERIAL AND METHODS}

\section{GNPs Synthesis, Characterization, and Conjugation with CTX and CDDP}

In the literature, sodium citrate $\left(\mathrm{Na}_{3} \mathrm{C}_{6} \mathrm{H}_{5} \mathrm{O}_{7}\right)$ is frequently used as a reducing agent for the synthesis of GNPs. ${ }^{19}$ Initially, $72 \mu \mathrm{L}$ of hydrochloroauric acid $\left(\mathrm{HAuCl}_{4}\right)$ (Sigma-Aldrich, Taufkirchen,
Germany) solution was added to $95 \mathrm{~mL}$ purified water and heated to $280^{\circ} \mathrm{C}$ on a magnetic stirrer. Following this procedure, sodium citrate solution (Sigma-Aldrich, Taufkirchen, Germany) was added to $5 \mathrm{~mL}$ of distilled water in a bath type sonicator for 30 minutes. Next, the sodium citrate solution was heated to $60^{\circ} \mathrm{C}$. When the hydrochloroauric acid solution reached $97^{\circ} \mathrm{C}$, the solution containing sodium citrate was added at $1 \mathrm{~mL} / \mathrm{s}$. The mixture was held on a heating plate $\left(280^{\circ} \mathrm{C}\right)$ for 10 minutes. The heating was stopped when the solution turned the color of red wine. After cooling, 8-arm-PEG- $\mathrm{NH}_{2}$ was added into the mixture and mixed using a probe-type ultrasonic mixer for 5 minutes under temperature control (not exceeding $25^{\circ} \mathrm{C}$ ). The nanodrug complex was obtained by binding of $25 \mu \mathrm{g}$ cetuximab (CTX) (Merck, Darmstadt, Germany) and conjugation of $5 \mu \mathrm{g}$ cisplatin $\left(\mathrm{Pt}\left(\mathrm{NH}_{3}\right)_{2} \mathrm{Cl}_{2}\right)(\mathrm{CDDP})$ (Sigma-Aldrich, Taufkirchen, Germany) to GNP surfaces functionalized with PEG-NH $\mathrm{NH}_{2}$ (Figure 1). The method detailed below was followed in the adsorption of $\mathrm{C} 225$ and CDDP on $\mathrm{PEG}-\mathrm{NH}_{2} / \mathrm{Au}$ nanoparticle surfaces. First, $10 \mathrm{~mL}$ of DI water solution containing $\mathrm{C} 225$ at initial concentrations of $50 \mu \mathrm{g} / \mathrm{mL}$ was prepared. To this solution, $\mathrm{Au} / \mathrm{PEG}-\mathrm{NH}_{2}$ nanoparticles functionalized with 50 $\mu \mathrm{g}$ PEG-NH $\mathrm{N}_{2}$ were added, and mixed with a magnetic stirrer for 4 hours at constant temperature without changing the $\mathrm{pH}$ of the solution. $\mathrm{C} 225$, which was not adsorbed to $\mathrm{Au} / \mathrm{PEG}-\mathrm{NH}_{2}$ surfaces, was centrifuged at $5000 \mathrm{rpm}$ for 15 minutes and removed from the upper phase of the centrifuge tube. All procedures were carried out in a completely dark environment to prevent drug degradation. Similarly, for the binding of cisplatin to the $\mathrm{Au} / \mathrm{PEG}-\mathrm{NH}_{2} / \mathrm{C} 225$ carrier system conjugated with $\mathrm{C} 225,10 \mathrm{~mL}$ of DI water solution containing CDPP at a concentration of $50 \mu \mathrm{g} / \mathrm{mL}$ was prepared and added to the solution containing $\mathrm{Au} / \mathrm{PEG}-\mathrm{NH}_{2} / \mathrm{C} 225$ carrier for 4 hours. It was mixed with a magnetic stirrer over a long period. Unbound CDDP was centrifuged and removed from the Au/PEG$\mathrm{NH}_{2} / \mathrm{C} 225 / \mathrm{CDDP}$ carrier system. The characterization of the GNPs was performed by scanning electron microscopy (SEM) and UVvisible spectroscopy.

\section{Cell Culture}

The radiotherapy-resistant oral cavity cancer cell line (UPCISCC-131) and fibroblast cell line (NIH-3T3) were purchased from DSMZ (Braunschweig, Germany) and ATCC (American Type

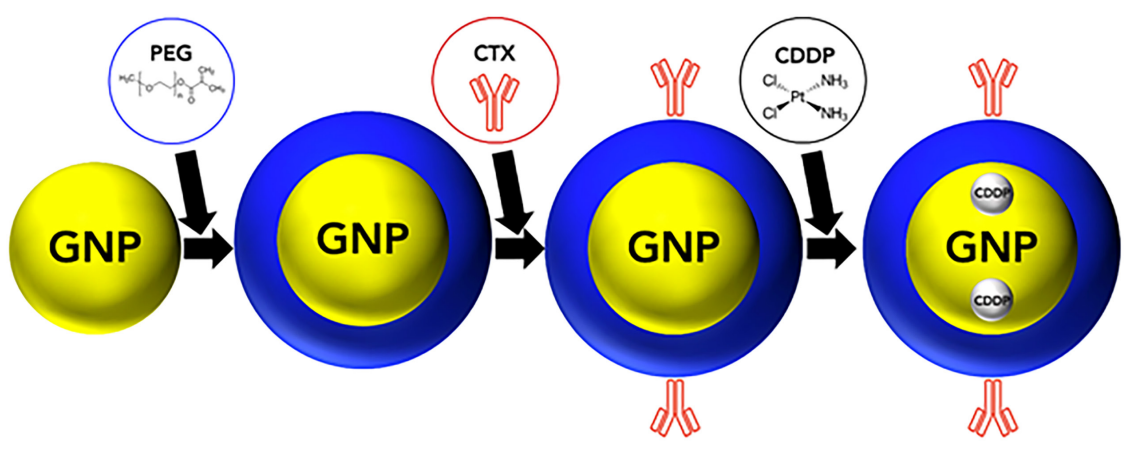

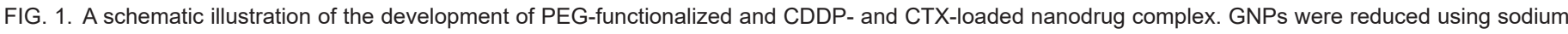

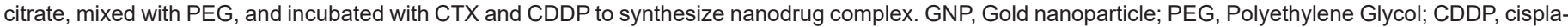
tin; CTX, Cetuximab. 
Culture Collection CRL-1658, Manassas, VA, USA), respectively. Cells were cultured with minimum essential medium (MEM) (Biochrom, Cambridge, UK) and supplemented with 10\% fetal bovine serum (FBS) (Biochrom, Cambridge, UK), $2 \mathrm{mM}$ L-Glutamine (Gibco, Grand Island, NY), and penicillin (100 units/mL)/streptomycin $(100 \mu \mathrm{g} / \mathrm{mL})$ (Gibco, Grand Island, NY) and were maintained in a humidified incubator $\left(5 \% \mathrm{CO}_{2}\right.$ at $\left.37^{\circ} \mathrm{C}\right)$.

\section{Transmission Electron Microscope}

A total of $2 \times 10^{6}$ cells were plated in $25 \mathrm{~cm}^{2}$ flasks for 24 hours, then exposed to $25 \mu \mathrm{g} / \mathrm{mL}$ of GNPs for 48 hours. Cells were trypsinized and washed with PBS, fixed in $2 \%$ glutaraldehyde in 0.1 $\mathrm{M}$ cacodylate buffer ( $\mathrm{pH} 7.4)$ for at least 2 hours at room temperature, and then post-fixed in $1 \% \mathrm{OsO}_{4}$ at $4{ }^{\circ} \mathrm{C}$ for 60 minutes. After fixation, the cells were cut into small blocks $\left(1 \mathrm{~mm}^{3}\right)$ and dehydrated in a graded series of ethanol $(50 \%, 70 \%, 80 \%, 90 \%$, $96 \%$, and $100 \%$ ), and blocks were placed in 1,2-propylene oxide (Merck, Haarlem, Netherlands)-Epon resin overnight. Semi-thin sections of $700 \mathrm{~nm}$ in thickness were cut using an Ultracut E ultramicrotome (Leica Microsystems, Wetzlar, Germany) and were stained by toluidine blue. Ultra-thin sections were obtained from selected blocks, mounted on copper grids, and examined using a transmission electron microscope (Zeiss-Sigma 500, Germany).

\section{Cell Viability Assay}

The effect of GNPs on cell viability was monitored by xCELLigence single plate (SP) system (RTCA SP Analyzer, Roche Applied Science, Mannheim, Germany, and ACEA Biosciences, San Diego, CA). UPCI-SCC-131 and NIH-3T3 cells were seeded at $1 \times 10^{4}$ cells/well into gold-coated 96-well E-plates and exposed to GNPs $(10,20,25,50$, and $100 \mu \mathrm{g} / \mathrm{mL})$ and nanodrug complex for 48 hours. The cells were automatically monitored every 15 minutes. The cell index value, which measures the relative change in electrical impedance to represent cell viability, was calculated for each sample by the RTCA Software Version 2.0. The percentage of viability was measured by the ratio of the cell index value of control cells to the nanodrug complex-applied cells. Each sample was assayed in triplicate, and 3 independent experiments were performed.

\section{In Vitro Irradiation}

For irradiation experiments, $5 \times 10^{2}$ cells containing GNPs were irradiated by $0.5,2,6$, and 8 Gy of $6 \mathrm{MV}$ radiotherapy (Siemens, Primus LINAK, Germany), then seeded in a 24-well plate in MEM media supplemented with $10 \%$ FBS. For each sample, 2 sets of 24-well plates were prepared, 1 was irradiated, while the other nonirradiated plate served as a negative control.

\section{Clonogenic Survival Assay}

Colony assay was performed to evaluate the therapeutic effects of radiotherapy on cell survival with and without GNPs. After irradiation, cells were kept in a humidified incubator for 10-21 days. Subsequently, they were fixed with $4 \%$ paraformaldehyde (SigmaAldrich, Taufkirchen, Germany) and stained using 1\% crystal violet (Sigma-Aldrich, Taufkirchen, Germany). Finally, the resulting colonies were counted. A colony was defined as a group of more than 50 cancer cells. An image of each colony was captured by UVP Gel Logic System (UVP Inc., Upland, CA).

The plating efficiency (PE) was calculated based on the survival of the control group ( $0 \mathrm{~Gy})$ and determined by:

$$
\operatorname{PE}(\%)=\frac{\text { Number of colonies counted }}{\text { Number of cells seeded }} \times 100
$$

The surviving fraction (SF) was calculated as:

$$
\mathrm{SF}=\frac{\text { Surviving colonies }}{\text { Cells plated } \times \mathrm{PE}}
$$

The contribution of GNPs and nanodrug complex for the increment of radiotherapy efficiency was measured by dose enhancement factor (DEF), calculated as the ratio of doses needed to give the same surviving fraction as that of the radiation-only control cells at the doses of $0.5,2,6$, and $8 \mathrm{~Gy}$. The sensitizer enhancement ratio (SER) was calculated as the radiation dose required for radiation alone, divided by the dose needed for different concentrations of GNP+ radiation at a survival fraction.

\section{Immunocytochemical Staining for EGFR Expression} EGFR antibody (NCL-L-EGFR, Novocastra Laboratories Ltd., Newcastle, UK) was obtained from Leica Biosystems. For immunocytochemistry, UPCI-SCC-131 cells were seeded into a $25 \mathrm{~cm}^{2}$ flask at a density of $1 \times 10^{6}$ and grown overnight for adherence, before being trypsinized and fixed in $10 \%$ buffered formalin. Sections were cut at $5 \mu \mathrm{m}$, mounted, and air-dried at room temperature. Then, all sections were deparaffinized in xylene, re-hydrated, and neutralized. Immunocytochemical staining was performed using the automated protocol of the Leica Bond III Automated Immunostainer (Leica Biosystems, Newcastle, UK). The slides were counterstained by hematoxylin $\&$ eosin. The skin was used as a positive control. EGFR staining was semi-quantitatively graded on a 4-point scale according to the intensity of staining ( 0 , negative; +, weak; ++ , moderate, and +++ , strong).

\section{Statistical Analysis}

All data were statistically evaluated using Graph Pad 8.0 software (San Diego, CA, USA). Experiments were carried out in triplicate, with results expressed as mean \pm standard deviation (SD). The Shapiro-Wilk test showed that data had a normal distribution. Statistically significant differences between 2 and more groups were calculated using the one-way ANOVA test with Tukey and Dunnett's post hoc tests. The survival curve was drawn using the linearquadratic model.

\section{RESULTS}

\section{The Characterization of GNPs}

The shape and size of GNPs were determined using SEM (Figure 2). The results suggested that GNPs were spherical, and the core diameters were approximately $15 \mathrm{~nm}$ (Figure 2A). The shape of the ultraviolet-visible (UV-Vis) spectra is shown in Figure 2B for single GNP, GNP with cisplatin (GNP-CDDP), GNP with 

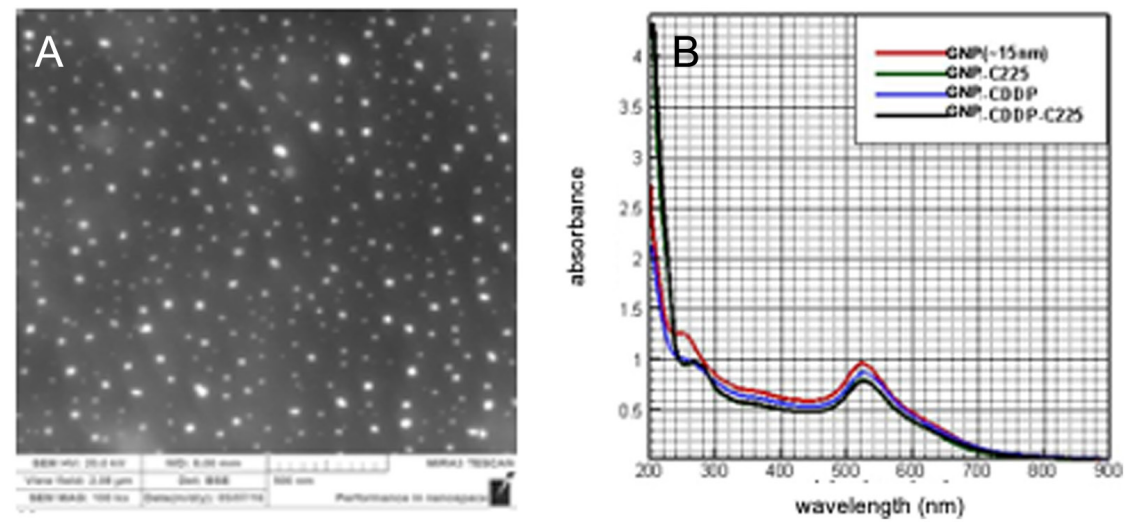

FIG. 2. A-B. The characterization of GNP was carried out using scanning electron microscope (SEM) and UV-visible spectroscopy. (A) SEM image showed that approximately $15 \mathrm{~nm}$ in diameter and spherical GNPs. (B) UV-vis spectrum of GNPs with CDDP and/or CTX showed absorption spectra at different wavelengths.

cetuximab (GNP-CTX), and GNP with cisplatin and cetuximab (GNP-CDDP-CTX). Figure 2B clearly shows that unconjugated GNP of $15 \mathrm{~nm}$ size gave a maximum peak at approximately 525 $\mathrm{nm}$ wavelength. On the other hand, the maximum peak of the nanocarrier systems produced with the agents conjugated to the particle surface was at a wavelength of $200 \mathrm{~nm}$, and had a higher absorbance value.

\section{Intracellular Localization of GNPs in UPCI-SCC-131 Cells} Nanodrug complexes have a key role in cytotoxicity due to their internalization by the cells. Prior to irradiation assay, transmission electron microscopy (Zeiss Sigma 500 electron microscope; Oberkochen, Germany) was used to determine the intracellular distribution of $15 \mathrm{~nm}$ GNPs, 48 hours after exposure. Figure 3 shows the oral cavity cancer cells that were treated with $25 \mu \mathrm{g} /$ $\mathrm{mL}$ GNPs. After internalization, autophagosomes were detected in all images.

\section{Immunocytochemical Staining}

EGFR protein expression levels in UPCI-SCC-131 cells were determined by the immunocytochemical staining method. While purple stains are indicative of nucleus stained with hematoxylin \& eosin, brown stains are indicative of EGFR expression. Immunocytochemistry data showed that EGFR expressions were scored as +++ , which is indicated to be strongly positive, as a result of staining (Figure 4).

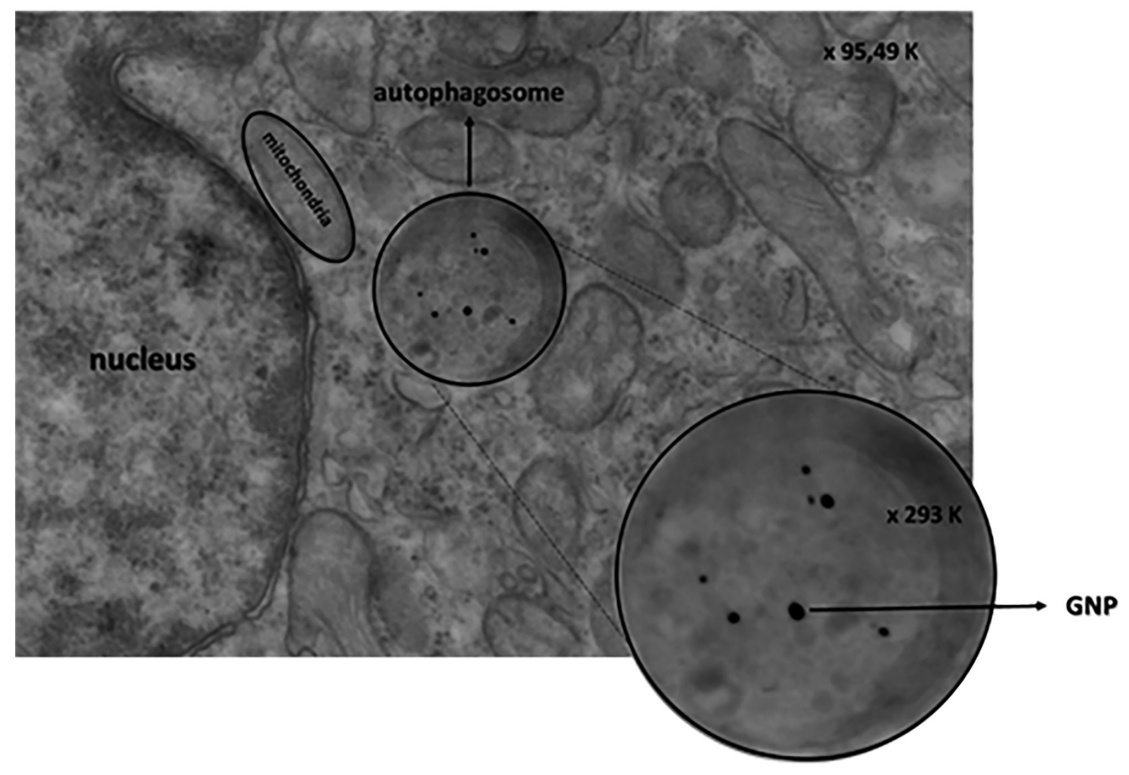

FIG. 3. Transmission electron microscopy images of UPCI-SCC-131 cells after exposure to $15 \mathrm{~nm}$ GNPs for 48 hours. The aggregates of GNPs were located in autophagosomes throughout the cell $(\times 95 \mathrm{~K}$ and $\times 293 \mathrm{~K})$. GNP, Gold nanoparticle. 


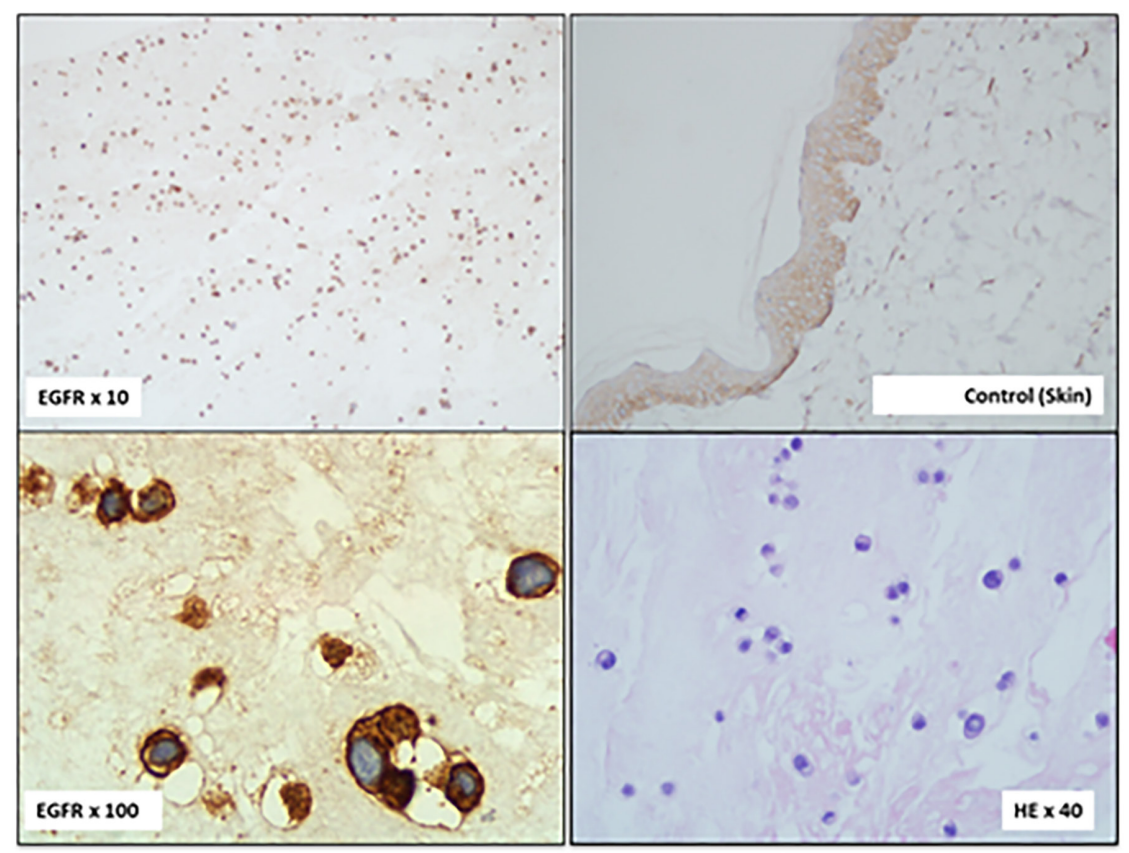

FIG. 4. Immunocytochemical staining for EGFR expression level of UPCI-SCC-131 cell was performed using EGFR mouse monoclonal antibody (1: 15 dilution) with Leica Bond Autostainer. EGFR-immunostained areas were shown at a magnification of 100x. The UPCI-SCC-131 cell showed strong EGFR staining intensity. EGFR, Epidermal Growth Factor Receptor.

\section{Real-Time Cell Viability in GNP-Treated UPCI-SCC-131 and NIH-3T3 Cells}

The xCELLigence assay was used to assess the effects of GNPs on the cell viability of the oral cavity cell line (Figure 5). The results showed that the dose-dependent effects of $15 \mathrm{~nm}$ GNPs were not cytotoxic to UPCI-SCC-131, and the $\mathrm{EC}_{50}$ values were $20 \mu \mathrm{g} / \mathrm{mL}$. According to nanodrug complex results, GNP-CDDP $(25 \mu \mathrm{g} / \mathrm{mL}-2.5 \mu \mathrm{g} / \mathrm{mL})$ decreased the cell viability compared to free CDDP at the dose of $2.5 \mu \mathrm{g} / \mathrm{mL}(P<.0001)$ and control $(P<$ $.0001)$. Similarly, we found that the GNP-CDDP-CTX nanodrug complex was more cytotoxic than CDDP-CTX on cell viability $(P$ $=.0001)$. Both CTX $(P=.2313)$ and GNP-CTX $(P=.0007)$ were non-toxic compared to control cells (Figure 6). We also evaluated

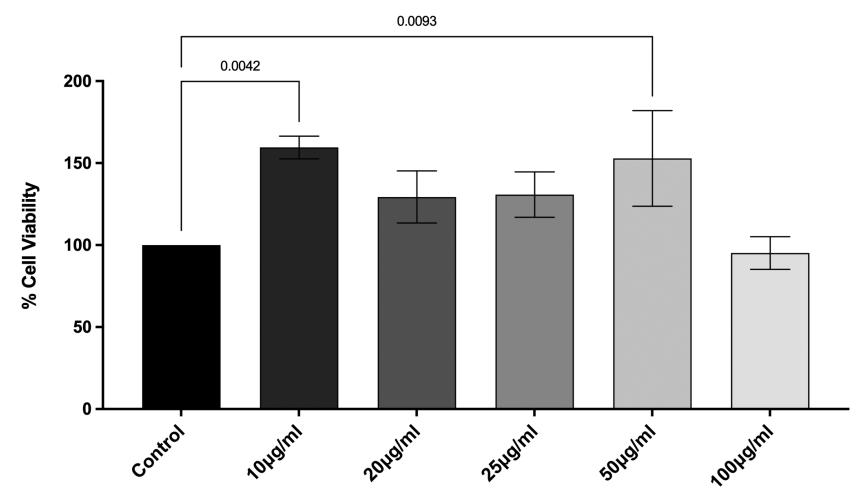

FIG. 5. The percentage of cell viability in different concentrations $(10,20,25$, 50 , and $100 \mu \mathrm{g} / \mathrm{mL}$ ) of $15 \mathrm{~nm}$ GNP-treated UPCI-SCC-131 cells for 48 hours. Data are expressed as mean \pm SD $(n=3)$. "P $\leq .05$. GNP: Gold Nanoparticle. the cell viability of the fibroblast cell line, NIH-3T3, containing the nanodrug complex. As can be seen in Supplementary Figure 1, no significant cell cytotoxicity was observed for 48 hours after GNP and GNP-CDDP treatment. However, CDDP, GNP-CDDP, and GNP-CDDP-CTX groups all indicated a decrease in cell viability.

\section{Clonogenic Survival Assay}

Colony formation was assayed to measure the cytotoxic effects of GNPs, based on the ability of a single cell to form a colony, and to compare the radiation sensitizing efficacies of GNPs on UPCISCC-131 cells. ${ }^{20}$ Figure 7A and 7B demonstrate the number of colonies formed in $25 \mu \mathrm{g} / \mathrm{mL}$ of GNP, GNP-CTX, CTX, GNPCDDP, CDDP, GNP-CTX-CDDP, CDDP-CTX, and control cells (without any agent). The effects of GNPs at the minimum doses ( 0.5 and 2 Gy) decreased the surviving fractions $\sim 1.2$-fold compared to control cells. With an increased radiation dose of GNPCTX, a decrease in cell survival was detected when compared with control and CTX alone (Figure 7C). The cells treated with the nanodrug complex, including GNP-CDDP, GNP-CDDPCTX, and the drugs (CDDP and CDDP-CTX) had no surviving colonies.

The DEF is the ratio of the dose with radiation alone to the dose with radiation + GNPs (Table 1). Notably, DEF values $>1$ indicate that GNPs are functioning as radiosensitizers. On the other hand, DEF values $<1$ show GNPs are radioprotectors. According to DEF values, GNPs were radiosensitizers at all doses starting from $0.5 \mathrm{~Gy}$. While the GNP-CTX complex was a radioprotector at a dose of $0.5 \mathrm{~Gy}$, it had a radiosensitizing effect at doses of 2, 6 , and 8 Gy. However, no colony formation was detected in cells 


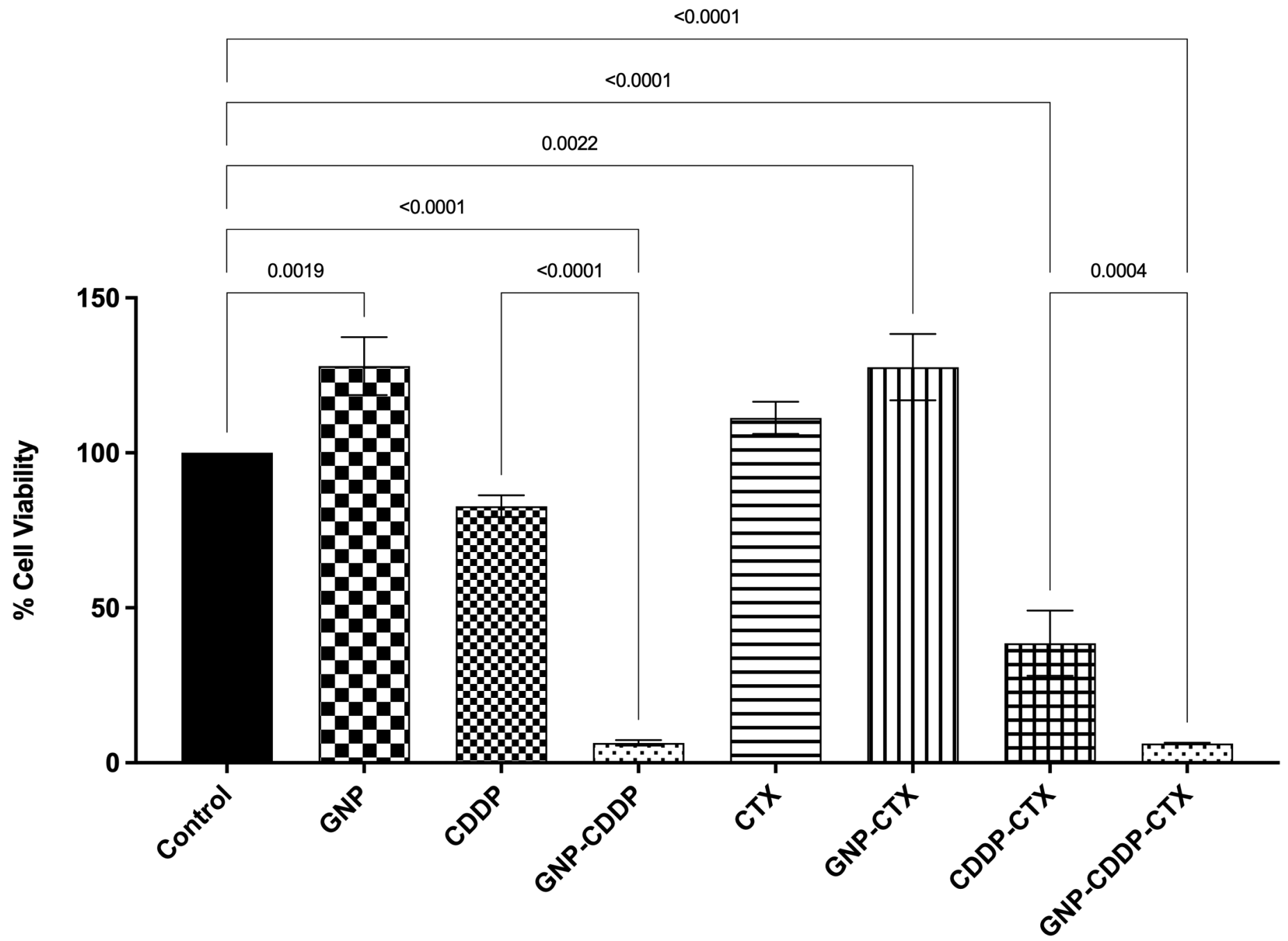

FIG. 6. The effects of nanodrug complex on cell viability in UPCI-SCC-131. Cells were incubated with $25 \mu \mathrm{g} / \mathrm{mL}$ GNPs, $2.5 \mu \mathrm{g} / \mathrm{mL} \mathrm{CDDP}$, and $25 \mu \mathrm{g} / \mathrm{mL}$ CTX for 48 hours. The percentage of cell viability was determined by using cell index values in GNP-treated UPCI-SCC-131 cells. Data are expressed as mean \pm SD $(n=3)$. ${ }^{*} \leq .05$. GNP: Gold nanoparticle, CDDP: Cisplatin, CTX: Cetuximab.

containing GNP-CDDP and GNP-CDDP-CTX after RT, therefore, DEF values for these nanodrug complexes were calculated as zero. The SER was calculated as 1.2 and 1.9, for GNP and GNPCTX, respectively.

\section{DISCUSSION}

Nanotechnology plays a significant role in medical approaches such as targeted therapies using nanocarriers, drug delivery systems, early detection, and diagnosis. The major problem associated with cancer treatment is the undesirable side effects and multidrug resistance, but toxicity may be significantly reduced by nanoparticle-mediated drug delivery and chemotherapeutic agents with high specificity in the target tissue.

GNPs can enhance the response to radiation therapy by exhibiting a radiosensitizing effect, and can also be used as nanodrug carriers due to their easy conjugation with other biomolecules such as chemotherapeutic agents or antibodies. ${ }^{21}$ In this study, we were able to develop a new and innovative nanodrug complex by successfully conjugating CTX, CDDP, and GNPs. Moreover, our literature survey demonstrated that this was the first experimental study involving an examination of the cytotoxic and radiosensitizer effects of the GNP-CTX-CDDP nanodrug complex evaluated on OSCC (UPCI-SCC-131 cells) in vitro at different megavoltage energies.

The human EGFR is associated with proliferation, angiogenesis, apoptosis, and metastasis, and is overexpressed in over $90 \%$ of head and neck cancers when compared with healthy cells. ${ }^{22}$ Because of its role, EGFR-targeted therapies may be utilized for patients with cancer. Cetuximab is a monoclonal antibody that binds specifically to the extracellular domain of human EGFR, and is approved for use as monotherapy after platinum-based therapies or in combination with radiotherapy. In the current context, we also determined that 

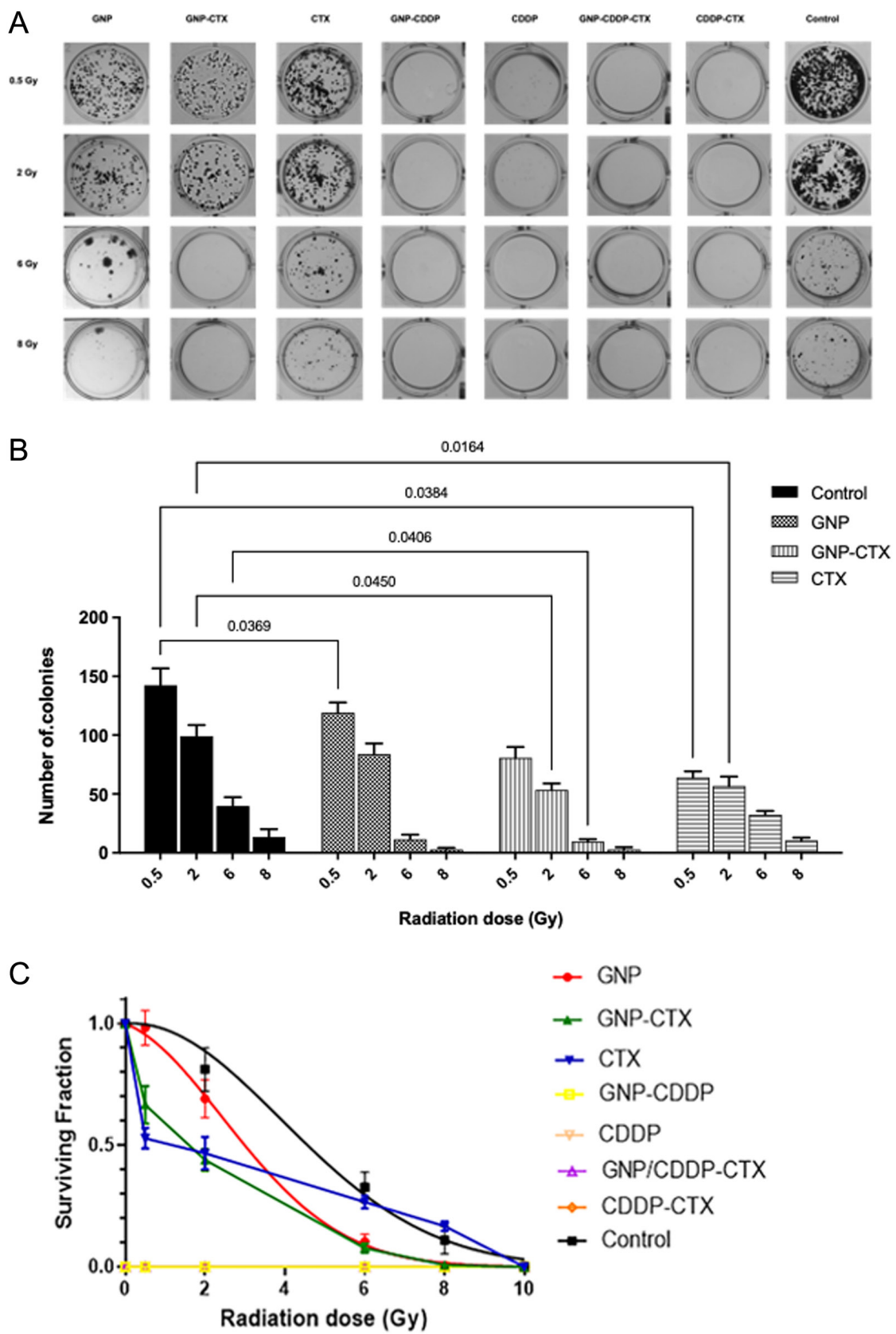

FIG. 7. A-C. Radiosensitization effects of GNPs in UPCI-SCC-131 cells (A) Images of colonies containing functionalized GNPs exposed to irradiation at different megavoltages was determined using clonogenic survival assay (B) Numbers of colonies was decreased with increasing doses of radiotherapy (C) The effects of GNPs on UPCI-SCC-131 cell survival was calculated by surviving fractions (SF), which showed the actual efficacy of the radiation effect on the cells. Data are expressed as mean \pm SD $(n=3)$. GNP, Gold nanoparticle; CDDP, Cisplatin; CTX, Cetuximab.

TABLE 1. Dose Enhancement Factor (DEF) Values* of Gold Nanoparticles (GNPs) After Radiation

\begin{tabular}{lccccc}
\hline Radiation Doses (Gy) & Control & GNP & GNP-CTX & GNP-CDDP & GNP-CDDP-CTX \\
\hline 0.5 & 1 & 1.20 & 0.87 & 0 & 0 \\
2 & 1 & 1.18 & 1.84 & 0 & 0 \\
6 & 1 & 3.13 & 4.25 & 0 & 0 \\
\hline
\end{tabular}

** DEF $>1$ : GNPs act as radiosensitizers, DEF $<1$ : GNPs act as radiosensitizers. CDDP: Cisplatin, CTX: Cetuximab. 
EGFR protein expressions in UPCI-SCC-131 cells showed strong positivity (Figure 4), therefore, we specifically aimed to design a nanodrug complex using GNP, CTX, and CDDP, a cytotoxic chemotherapeutic agent particularly used as a radiosensitizer in head and neck cancers. In a recent article, Eskiizmir et al. determined the effects of CTX with $\mathrm{IC}_{50}$ doses of $400 \mu \mathrm{g} / \mathrm{mL}$ on cell viability in UPCI-SCC-131 cancer cells. ${ }^{23}$ In this context, CTX was used as a specific targeting agent rather than a cytotoxic agent; therefore, the much lower dose of $25 \mu \mathrm{g} / \mathrm{mL}$ was preferred for this study.

The transmission electron microscope, which is used to determine the localization of GNPs within the cell, clearly revealed the efficient entry of GNPs into the cell. Furthermore, it was shown that GNPs were located in the autophagosome throughout the cell. According to xCELLigence results, different concentrations of PEGylated GNPs, of $15 \mathrm{~nm}$ diameter, were non-toxic on cell viability compared to control cells at 48-hour incubation; therefore $25 \mu \mathrm{g} / \mathrm{mL}$ was the chosen concentration of GNPs as a nanocarrier. The toxicity of nanoparticles depends on different factors such as their size, surface, and shape. It was shown that small sizes of gold clusters (1.2 and $1.4 \mathrm{~nm}$ ) had higher cytotoxicity on necrosis and apoptosis than $15 \mathrm{~nm}$ GNPs. ${ }^{24,25}$ In concordance with our results, Leve et al. failed to show the cytotoxic effect of GNPs on colorectal cancer cells (Caco-2, HT-29, and HCT-116) for 24 and 48 hours. ${ }^{26}$ On the basis of the present cell viability results, GNPCDDP and GNP-CDDP-CTX showed the greatest reduction in obtaining statistically significant differences in comparison with control group for this study. Davidi et al. developed a nanosystem which acts as a radiosensitizer, drug carrier, and tumor-imaging agent for head and neck cancers. They synthesized cisplatin- and glucose-coated nanoparticles $(20 \mathrm{~nm})$, and similar to our results, they showed that their nanosystem penetrated tumor cells and led to a decrease in cell viability. ${ }^{27}$ We have also investigated the effects of the nanodrug complex on cell viability in a normal cell line, NIH-3T3, and found no statistically significant difference in cell viability on treatment with GNP and GNP-CDDP. However, GNP_CDDP-CTX may have shown a synergistic effect and enhanced the cytotoxic activity of the nanodrug complex, and this may lead to a reduction in the cell viability of NIH-3T3. These are noteworthy contributions to the literature. Vechia et al. ${ }^{28}$ evaluated the cytotoxicity of citrate-capped GNPs in murine fibroblast (NIH-3T3) and found that GNPs tended to decrease cell viability in a dose-dependent manner. In another in vitro study, Chueh et al. ${ }^{29}$ showed that GNPs reduced cytotoxicity as a survival mechanism by autophagy induction on NIH-3T3 cells. On the other hand, it was reported that doxorubicin-conjugated GNPs decreased the cell viability of NIH-3T3 cells compared to control cells. ${ }^{30}$ Hence, the parameters such as target cell type, size, or concentration of the nanoparticle need to be carefully chosen when assessing the toxicity of nanoparticles.

Another main goal of the present study was to examine the systematic effects of combined therapy by stimulating X-ray containing GNPs. The UPCI-SCC-131 cell line is known to have ATM (ataxia-telangiectasia mutated) deficiency, causing resistance to radiotherapy. ${ }^{31}$ Colony formation assay showed that there was a reduction in colony numbers after the treatment with GNPs and nanodrug complex combined with radiotherapy in UPCISCC-131 cells. In particular, GNP-CTX with radiotherapy improved the efficacy of radiotherapy, compared to the effects of GNP or free CTX alone on cell viability. This showed that GNP$\mathrm{CTX}$ in combination with radiotherapy produced a great synergism on UPCI-SCC-131 cell survival even at minimal radiotherapy doses such as 2 Gy. Popovtzer et al. evaluated the effectiveness and toxicity of targeted GNP with CTX followed by conventional $6 \mathrm{MV}$ radiotherapy in head and neck squamous cancer cells (HNSCC). ${ }^{32}$ Their results showed that a GNP/CTX injection was associated with a significant improvement in tumor radiosensitivity, relative to the other modalities. In our study, cells containing CDDP (GNP/CDDP_CTX, GNP_CDDP, CDDP_CTX, and free CDDP) failed to form colonies after radiotherapy, possibly related to the use of high-dose cisplatin $(2.5 \mu \mathrm{g} / \mathrm{mL})$.

We also aimed to measure the DEF in the presence of the GNPs at different radiotherapy doses. The DEF (2 Gy) and DEF (6 Gy) of GNP were found as 1.18 and 3.13, respectively. This revealed that the combination of GNPs and radiotherapy showed enhanced cytotoxic effects in vitro. In conjunction with this, DEF values for GNP-CTX were calculated as 1.84 and 4.25 at 2 and 6 Gy, respectively. The DEF of GNPs at all radiotherapy doses was above 1, which shows that $15 \mathrm{~nm}$ GNPs and functionalized GNP-CTX may be good radiosensitizers, even at concentrations as low as $25 \mu \mathrm{g} / \mathrm{mL}$, when used with megavoltage X-ray irradiation. Previous studies have reported that using the GNP-based radiotherapy enhanced the therapeutic index for the treatment of cancer with high DEF and SER values. ${ }^{33-35}$ The sensitization enhancement ratio (SER), which is used to evaluate how effectively radiosensitizers decrease cell survival, was calculated as 1.2 and 1.9 for GNP and GNP-CTX, respectively, at 2 Gy. These high SER values indicate that GNPs were able to reach a maximum radiosensitization.

This study showed that the PEGylated GNP nanodrug complexes are potentially effective in generating high cytotoxicity at low doses by significantly potentiating radiotherapy activity in RTresistant oral cavity cancer cells, and successfully conjugating with CTX to achieve an active targeted nanodrug complex. It is also clearly possible to develop the nanodrug complex with active/passive targeted radiosensitizing properties.

The 2 major advantages of our nanoparticle system are their excellent biocompatibility and low biological toxicity compared with other traditional agents such as cisplatin. When coupled with in vitro X-ray irradiation, the nanodrug system showed more effectiveness at low doses, thus potentially decreasing the extent of radiotherapy for patients.

For the first time in the literature, in this study, we successfully synthesized the GNP-conjugated cisplatin and cetuximab complexes as nanodrugs, and evaluated the efficiency of combination therapy with radiotherapy in the presence of the nanodrug complex for the radiotherapy-resistant oral cavity cancer cell line. 
Based on in vitro radiotherapy, PEG-coated GNPs may be used for drug delivery and improve the efficiency of possible applications in radiotherapy. These findings will provide a valuable approach to apply the highly effective nano-radiosensitizer for the treatment of oral cavity cancers. Further investigation is needed into the differential radiosensitizing efficacies of GNPs at other concentrations, or with larger or smaller sizes; however, this work will require in vivo studies.

Ethics Committee Approval: As stated by The Scientific and Technological Research Council of Turkey (TUBITAK), ethics committee approval is not required for in vitro cell culture studies.

Data Sharing Statement: Author elects to not share data.

Author Contributions: Concept- Y.B.; Design- Y.B., G.E., K.Y., Z.A.; Supervision- Y.B., G.E., K.Y.; Funding- B.Y.; Materials- Ş.İ-S; Data Collection and/or Processing- Ş.İ-S., TB.E., D.A., G.Ç-K, Z.A.; Analysis and/or Interpretation- Ş.İ-S, TB.E., D.A., G.Ç-K, Z.A.; Literature Review- Ş.İ-S., E.D.; Writing- Ş.İ-S., E.D.; Critical Review- Y.B., G.E., K.Y.

Conflict of Interest: The authors have no conflict of interest to declare.

Funding: This study was supported by The Scientific and Technological Research Council of Turkey (TUBITAK)-115S476 and Dokuz Eylül University Scientific Research Coordination Unit. Project Number: 2018.KB.SAG.080.

\section{REFERENCES}

1. Kamangar F, Dores GM, Anderson WF. Patterns of cancer incidence, mortality, and prevalence across five continents: defining priorities to reduce cancer disparities in different geographic regions of the world. J Clin Oncol. 2006;24(14):2137-2150. [CrossRef]

2. Marur S, Forastiere AA. Head and neck cancer: changing epidemiology, diagnosis, and treatment. Mayo Clin Proc. 2008;83(4):489-501. [CrossRef]

3. Kim CK, Ghosh P, Rotello VM. Multimodal drug delivery using gold nanoparticles. Nanoscale. 2009;1(1):61-67. [CrossRef]

4. McQuaid HN, Muir MF, Taggart LE, et al. Imaging and radiation effects of gold nanoparticles in tumour cells. Sci Rep. 2016;6:19442. [CrossRef]

5. Butterworth KT, McMahon SJ, Currell FJ, Prise KM. Physical basis and biological mechanisms of gold nanoparticle radiosensitization. Nanoscale. 2012;4(16):48304838 [CrossRef].

6. Zhang X. Gold nanoparticles: recent advances in the biomedical applications. Cell Biochem Biophys. 2015;72(3):771-775. [CrossRef]

7. Zhang X, Xing JZ, Chen J, et al. Enhanced radiation sensitivity in prostate cancer by gold-nanoparticles. Clin Invest Med. 2008;31(3):E160-E167. [CrossRef]

8. Jeremic B, Aguerri AR, Filipovic N. Radiosensitization by gold nanoparticles. Clin Transl Oncol. 2013;15(8):593-601. [CrossRef]

9. Pottier A, Borghi E, Levy L. New use of metals as nanosized radioenhancers. Anticancer Res. 2014;34(1):443-453.

10. O-charoenrat P, Rhys-Evans PH, Archer DJ, Eccles SA. C-erbB receptors in squamous cell carcinomas of the head and neck: clinical significance and correlation with matrix metalloproteinases and vascular endothelial growth factors. Oral Oncol. 2002;38(1):73-80. [CrossRef]

11. Sarkis SA, Abdullah BH, Abdul Majeed BA, Talabani NG. Immunohistochemical expression of epidermal growth factor receptor (EGFR) in oral squamous cell carcinoma in relation to proliferation, apoptosis, angiogenesis and lymphangiogenesis. Head Neck Oncol. 2010;2:13. [CrossRef]

12. Ryott M, Wangsa D, Heselmeyer-Haddad K, et al. EGFR protein overexpression and gene copy number increases in oral tongue squamous cell carcinoma. Eur J Cancer. 2009;45(9):1700-1708. [CrossRef]

13. Ang KK, Berkey BA, Tu X, et al. Impact of epidermal growth factor receptor expression on survival and pattern of relapse in patients with advanced head and neck carcinoma. Cancer Res. 2002;62(24):7350-7356.
14. Galizia G, Lieto E, De Vita F, et al. Cetuximab, a chimeric human mouse antiepidermal growth factor receptor monoclonal antibody, in the treatment of human colorectal cancer. Oncogene. 2007;26(25):3654-3660. [CrossRef]

15. Li S, Schmitz KR, Jeffrey PD, et al. Structural basis for inhibition of the epidermal growth factor receptor by cetuximab. Cancer Cell. 2005;7(4):301-311. [CrossRef]

16. Bonner JA, Harari PM, Giralt J, et al. Radiotherapy plus cetuximab for squamouscell carcinoma of the head and neck. NEngl J Med. 2006;354(6):567-578. [CrossRef]

17. Burtness B, Goldwasser MA, Flood W, et al. Phase III randomized trial of cisplatin plus placebo compared with cisplatin plus cetuximab in metastatic/recurrent head and neck cancer: an Eastern Cooperative Oncology Group study. $J$ Clin Oncol. 2005;23(34):8646-8654. [CrossRef]

18. Zhang XD, Wu D, Shen X, et al. Size-dependent radiosensitization of PEG-coated gold nanoparticles for cancer radiation therapy. Biomaterials. 2012;33(27):64086419. [CrossRef]

19. Franken NA, Rodermond HM, Stap J, Haveman J, van Bree C. Clonogenic assay of cells in vitro. Nat Protoc. 2006;1(5):2315-2319. [CrossRef]

20. Ma N, Wu FG, Zhang X, et al. Shape-dependent radiosensitization effect of gold nanostructures in cancer radiotherapy: comparison of gold nanoparticles, nanospikes, and nanorods. ACS Appl Mater Interfaces. 2017;9(15):13037-13048. [CrossRef]

21. Pullambhatla M, Rowe SP, Lisok A, et al. Enhancement of radiotherapy with human mesenchymal stem cells containing gold nanoparticles. Tomography. 2020;6(4):373378. [CrossRef]

22. Nair S, Trummell HQ, Rajbhandari R, et al. Novel EGFR ectodomain mutations associated with ligand-independent activation and cetuximab resistance in head and neck cancer. PLoS One. 2020;15(2):e0229077. [CrossRef]

23. Eskiizmir G, Çalıbaşı G, Uysal T, Ellidokuz H, Baskın Y. Cetuximab alone has a dose-dependent antitumor effect in oral cavity cancer cells: an in vitro study. ENT Update. 2016;6(3):105-109. [CrossRef]

24. Pan Y, Neuss S, Leifert A, et al. Size-dependent cytotoxicity of gold nanoparticles. Small. 2007;3(11):1941-1949. [CrossRef]

25. Pan Y, Leifert A, Ruau D, et al. Gold Nano- particles of diameter $1.4 \mathrm{~nm}$ trigger necrosis by oxidative stress and mitochondrial damage. Small. 2009;5(18):20672076. [CrossRef]

26. Leve F, Bonfim DP, Fontes G, Morgado-Díaz JA. Gold nanoparticles regulate tight junctions and improve cetuximab effect in colon cancer cells. Nanomedicine. 2019;14(12):1565-1578. [CrossRef]

27. Davidi ES, Dreifuss T, Motiei M, et al. Cisplatin-conjugated gold nanoparticles as a theranostic agent for head and neck cancer. Head Neck. 2018;40(1):70-78. [CrossRef]

28. Vechia ICD, Steiner BT, Freitas ML, et al. Comparative cytotoxic effect of citratecapped gold nanoparticles with different sizes on noncancerous and cancerous cell lines. J Nanopart Res. 2020;22(6):133. [CrossRef]

29. Chueh PJ, Liang RY, Lee YH, Zeng ZM, Chuang SM. Differential cytotoxic effects of gold nanoparticles in different mammalian cell lines. J Hazard Mater. 2014;264:303-312. [CrossRef]

30. Aryal S, Grailer JJ, Pilla S, Steeber DA, Gong S. Doxorubicin conjugated gold nanoparticles as water-soluble and $\mathrm{pH}$-responsive anticancer drug nanocarriers. $J$ Mater Chem. 2009;19(42):7879. [CrossRef]

31. Sankunny M, Parikh RA, Lewis DW, et al. Targeted inhibition of ATR or CHEK1 reverses radioresistance in oral squamous cell carcinoma cells with distal chromosome arm 11q loss. Genes Chromosomes Cancer. 2014;53(2):129-143. [CrossRef]

32. Popovtzer A, Mizrachi A, Motiei M, et al. Actively targeted gold nanoparticles as novel radiosensitizer agents: an in vivo head and neck cancer model. Nanoscale. 2016;8(5):2678-2685. [CrossRef]

33. Ma N, Jiang YW, Zhang X, et al. Enhanced radiosensitization of gold nanospikes via hyperthermia in combined cancer radiation and photothermal therapy. ACS Appl Mater Interfaces. 2016;8(42):28480-28494. [CrossRef]

34. Ma N, Liu P, He N, et al. Action of gold nanospikes-based nanoradiosensitizers: cellular internalization, radiotherapy, and autophagy. ACS Appl Mater Interfaces. 2017;9(37):31526-31542. [CrossRef]

35. Zhang X, Chen X, Jiang YW, et al. Glutathione-depleting gold nanoclusters for enhanced cancer radiotherapy through synergistic external and internal regulations. ACS Appl Mater Interfaces. 2018;10(13):10601-10606. [CrossRef] 


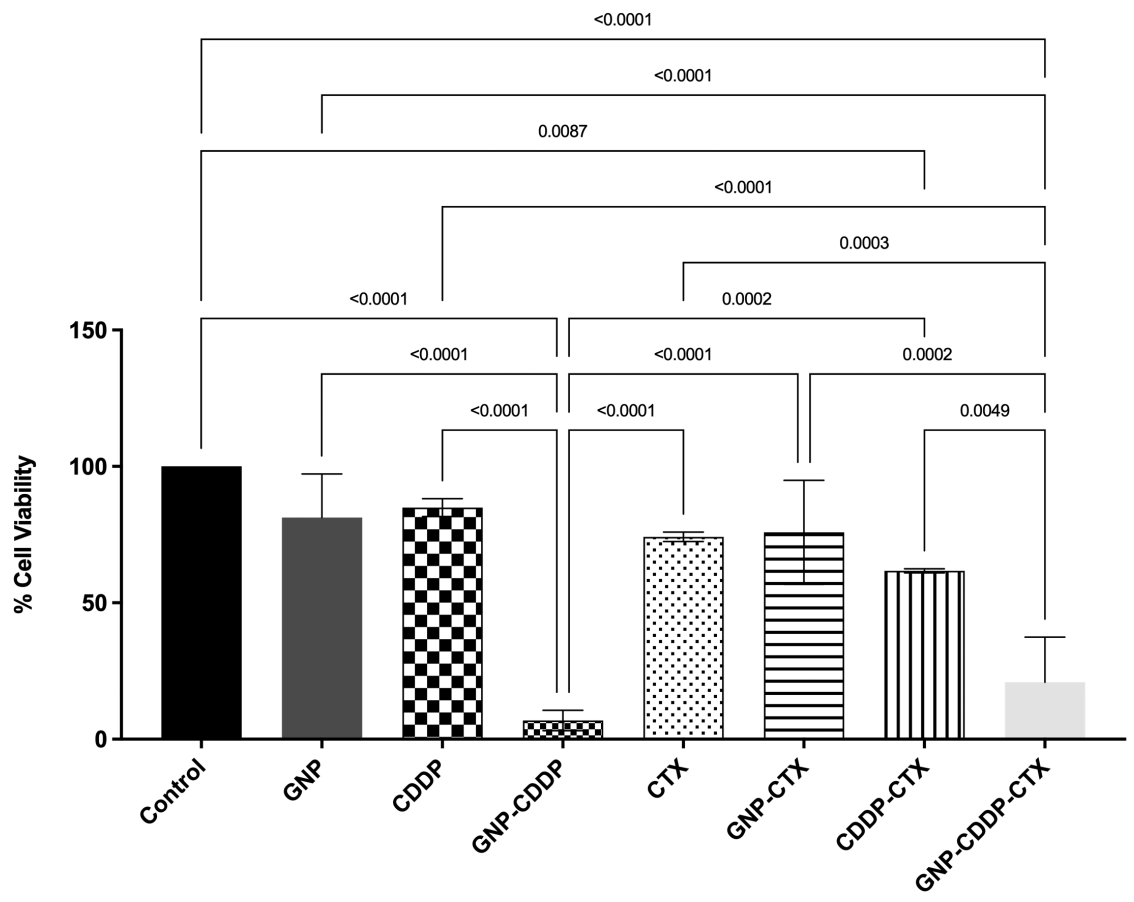

Supplementary FIG. 1. Cell viabilities of NIH-3T3 cells studied by using the $\mathrm{x}$-CELLigence RTCA system, and the cells were treated in medium containing $25 \mu \mathrm{g} / \mathrm{mL}$ GNPs, $2.5 \mu \mathrm{g} / \mathrm{mL}$ CDDP, and $25 \mu \mathrm{g} / \mathrm{mL}$ CTX. Data are expressed as mean $\pm \operatorname{SD}(n=3) .{ }^{*} P \leq .05$ 